\title{
A Novel Fuzzy Logic Based Load Frequency Control for Multi-Area Interconnected Power Systems
}

\author{
Diem-Vuong Doan \\ Faculty of Control and Automation \\ Electric Power University \\ Hanoi, Vietnam \\ vuongdd@epu.edu.vn
}

\author{
Khoat Nguyen \\ Faculty of Control and Automation \\ Electric Power University \\ Hanoi, Vietnam \\ nkn.research@gmail.com
}

\author{
Quang-Vinh Thai \\ Institute of Information Technology \\ Vietnam Academy of Science and Technology \\ Hanoi, Vietnam \\ tqvinh@ioit.ac.vn
}

\begin{abstract}
This study focuses on designing an effective intelligent control method to stabilize the net frequency against load variations in multi-control-area interconnected power systems. Conventional controllers (e.g. Integral, PI, and PID) achieve only poor control performance with high overshoots and long settling times. They could be replaced with intelligent regulators that can update controller parameters for better control quality. The control strategy is based on fuzzy logic, which is one of the most effective intelligent strategies and can be a perfect substitute for such conventional controllers when dealing with network frequency stability problems. This paper proposes a kind of fuzzy logic controller based on the PID principle with a 49-rule set suitable to completely solve the problem of load frequency control in a two-area thermal power system. Such a novel PIDlike fuzzy logic controller with modified scaling factors can be applied in various practical scenarios of an interconnected power system, namely varying load change conditions, changing system parameters in the range of $\pm \mathbf{5 0 \%}$, and considering Governor Dead-Band (GDB) along with Generation Rate Constraint (GRC) nonlinearities and time delay. Through the simulation results implemented in Matlab/Simulink software, this study demonstrates the effectiveness and feasibility of the proposed fuzzy logic controller over several counterparts in dealing with the load-frequency control of a practical interconnected power system considering the aforesaid conditions.
\end{abstract}

Keywords-Load Frequency Control (LFC); Fuzzy-PID controller; PID controller; uncertainties; nonlinearities

\section{INTRODUCTION}

Due to the random change of load in a power system, electrical energy varies continuously. This affects the system's operating frequency, leading to a deviation of the network frequency from the nominal value. A modern power system network has several control areas. For the stable operation of power subsystems, the total generation of each control area must match with the total load demand plus associated system losses, regulate system frequency, and exchange tie-line power accordingly. This is defined as the Load Frequency Control (LFC) or Automatic Generation Control (AGC), which plays an important role in power system operation and control. The LFC strategy aims to continuously monitor the system frequency and the tie-line power. It also calculates net changes of these two parameters from their nominal values, which is known as Area Control Error (ACE), in order to control the valve settings of prime movers with a goal of forcing ACE signals to acceptable values. Considered to be a crucial part of AGC, the LFC strategy drives ACE signals to desirable values, meaning both frequency and tie-line power deviations should be treated to be near zero with allowable tolerance.

There are several reports regarding the LFC problem. In [1], the authors designed a fuzzy-PI controller to control the load frequency for a six-area power system with non-reheat turbines. Authors in [2] proposed a PID hierarchical frequency controller for four-area interconnection power systems. The control structure used PID controller to prevent GRC from generating. The author in [3] proposed the optimal sliding control method Ho load frequency (SMLFC) for power system with time delay. In [4], a fuzzy controller was proposed to find the optimal parameters for the PID frequency controller of a three-area power system. In [5], a neural controller was proposed, designed to automatically and continuously adjust the parameters of the PID controller according to the change of the control error area. In [6], the control plant under consideration was a three-area electric power system composed of wind, heat, and hydraulic turbines. The authors gave control methods that were considered to be advanced, such as PID, FOPID, FPID, and FFOPID, which were designed based on ITAE objective function. In [7], the method used was a hybrid controller hPSO-PS for two-area power systems without heat recovery, each with two generators. In [8], a Model Predictive Controller (MPC) was used to control a multi-connected power system with four areas and eight generators. In [9], the 
QOGWO algorithm was used to optimize the parameters of the PID controller based on the ITAE objective function. In [10], the COA algorithm was used to optimize the parameters of the PIaDF controller. The controller was used to control the load frequency for a multi-connection system with two nonrecovery areas, two multi-generator areas, and three multigenerator hydrogen turbine areas. In [11], the authors proposed the T-SMC sliding controller for a two-area power system with wind turbines. In [12], the authors studied a virtual inertial controller to stabilize the frequency in a two-area power system with wind and solar renewable energy supplies. In [13], Fractional Order Proportional-Integral-Derivative (FOPID) and Tilted-Integral-Derivative (TID) controllers were applied in the design of LFC for a two-area diverse-unit power system. Tuneable parameters were adjusted via an improved particle swarm optimization algorithm which was powered by chaotic parameters and a crossover operator to find a globally optimal solution. In [14], a novel evolution (MDE) algorithm optimized fuzzy PID controller was proposed for the LFC of a two-area power system.

In order to stabilize the frequency in an interconnected power system, many problems arising in the system affect its control quality. These include devices with nonlinear system components such as: GDB (Governor Dead Band), GRC (Generation Rate Constraint), time delay in the system, changes of parameters of electrical equipment, and varying operating loading conditions. All the above factors make the system unstable, leading to fluctuations of the operating frequency. The frequency change affects greatly the devices in the system:

- Most AC motors run at speeds that are directly related to frequency. The speed and induced Electro Motive Force (EMF) may vary because of the change of frequency of the power circuit.

- When operating at frequencies below $49.5 \mathrm{~Hz}$ some types of steam turbine certain rotor states undergo excessive vibration.

- The change in frequency can cause maloperation of power converters by producing harmonics.

- For power stations running in parallel it is necessary that the frequency of the network must remain constant for the synchronization of generators.

- Many devices connected to the grid will only work properly when the input frequency is within a certain range.

- The inductances of the inductive elements (e.g. transformers) are chosen based on the switching frequency. Changes in the frequency will cause disturbances in the output and may even cause the supply's control system to become unstable

The traditional PID controller, controller parameters are not updated when the system encounters the above problems. Therefore, the fuzzy - PID controller [15] is studied in this paper to solve the load frequency control problem. Although they do not have an apparent structure of PID controllers, fuzzy logic controllers are considered to be nonlinear PID controllers with parameters that can be determined on-line based on the error signal and its time derivative. The response results of the system are compared with the Genetic Algorithm tuned PI (GA-PI) [16], Bacterial Foraging Optimization Algorithm tuned PI (BFOA PI) [16], BFOA-PSO optimized PI controller [17], fuzzy PI controller [18], and Fractional PID (FPID) [19].

\section{INTERCONNECTED POWER SYSTEM MODELING}

Each interconnected power system consists of several subsystems called control areas. A control area should be considered as a power station including several elements, namely governor, turbine, load, and generator. These elements are connected to be the core of a power plant. Their mathematical models are described below.

\section{A. Speed Governor Model}

A typical model of governors is depicted in Figure 1 [1]. This model can be mathematically expressed as:

$$
\Delta P_{g}(s)=\frac{1}{1+s T_{g}}\left(\Delta P_{c}(s)-\frac{1}{R} f(s)\right)
$$

where $R$ is the speed regulation of the governor, $T_{g}$ is the time constant of the speed the governor.

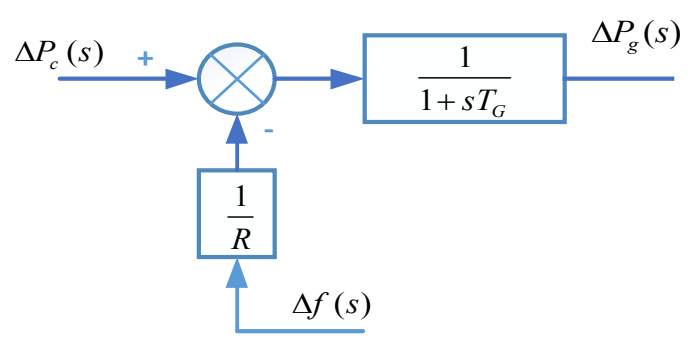

Fig. 1. Speed governor model.

\section{B. Thermal Turbine Models}

Thermal turbines are widely used in power plants. Technically, they are classified into two types: non-reheat and reheat turbines. The non-reheat model is shown in Figure 2. The following expression is obtained:

$$
\mathrm{G}_{t}(s)=\frac{P_{t}(s)}{P_{g}(s)}=\frac{1}{1+s T_{c h}}
$$

where $T_{c h}$ is the non -reheat time constant.

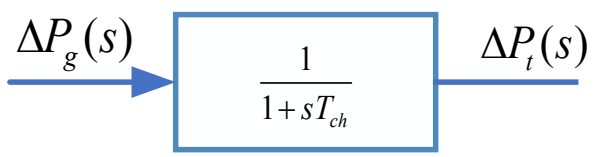

Fig. 2. Non - reheat turbine model.

The reheat turbine model is presented in Figure 3 and the mathematical model in (3).

$$
\mathrm{G}_{t}(s)=\frac{P_{t}(s)}{P_{g}(s)}=\frac{F_{h p} T_{r h} s+1}{T_{c h} T_{r h} s^{2}+\left(T_{c h}+T_{r h}\right) s+1}
$$


where $T_{r h}$ and $F_{h p}$ are the low pressure reheat time constant and the high pressure stage respectively.

$$
\stackrel{\Delta P_{g}(s)}{\frac{F_{h p} T_{r h} s+1}{T_{c h} T_{r h} s^{2}+\left(T_{c h}+T_{r h}\right) s+1}} \Delta P_{t}(s)
$$

Fig. 3. Reheat turbine model.

\section{Generator - Load Model} 4:

Equation (4) is obtained from the block diagram in Figure

$$
\Delta \mathrm{F}(s)=\frac{1}{M s+D}\left(\Delta P_{t}(s)-\Delta P_{d}(s)\right)
$$

where $M$ is the inertia constant of the generator and $D$ is the load damping constant.

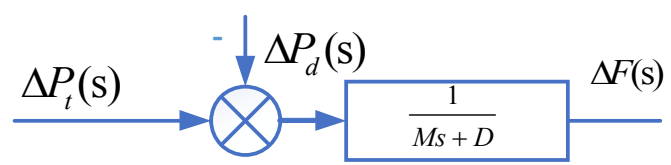

Fig. 4. Generator - load model.

Figure 5 shows the block diagram of a two-area interconnected power system with GDB and GRC. The system is represented by the state space shown in Appendix A.

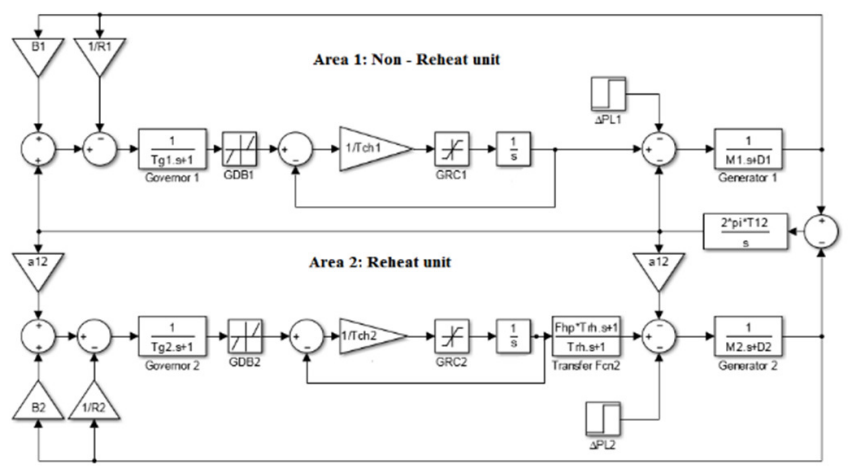

Fig. 5. Block diagram of a two-area interconnected non-reheat thermalreheat thermal power system with GRC and GRC.

The control objectives of the LFC in a multi-area interconnected power system are mainly to control the frequency variation, ACE, and tie-line power deviation in the areas towards zero while the system has many nonlinear, uncertain components and varying operating load conditions.

\section{DESIGN OF THE FUZZY-PID CONTROLLER}

The fuzzy - PID controller studied in this paper is compared in terms of control quality with other controllers to prove its superiority. The PID controller [15] is characterized by 3 parameters: $K_{p}, K_{d}$, and $K_{i}$. Assuming that $K_{p}$ and $K_{d}$ are always in the range $\left[K_{p \min }, K_{\text {max }}\right]$ and $\left[K_{d \min }, K_{d \max }\right]$, it is reasonable to define the following equations:

$$
\begin{gathered}
K_{p}^{\prime}=\left(K_{p}-K_{p \min }\right) /\left(K_{p \max }-K_{p \min }\right) \\
K_{d}^{\prime}=\left(K_{d}-K_{\mathrm{d} \min }\right) /\left(K_{\mathrm{d} \max }-K_{\mathrm{d} \min }\right) \\
T_{i}=\alpha T_{d} \quad(7) \\
K_{i}=K_{p} / \alpha \mathrm{T}_{d}=K_{p}^{2} /\left(\alpha T_{d}\right) \\
K_{p \min }=0.32 K_{u} \\
K_{p \max }=0.6 K_{u} \\
K_{\mathrm{d} \min }=0.08 K_{u} \mathrm{~T}_{u} \\
K_{\mathrm{d} \max }=0.15 K_{u} T_{u}
\end{gathered}
$$

where $K_{u}$ and $T_{u}$ are, respectively, the gain and the period of the oscillation at the stability limit under P-control.

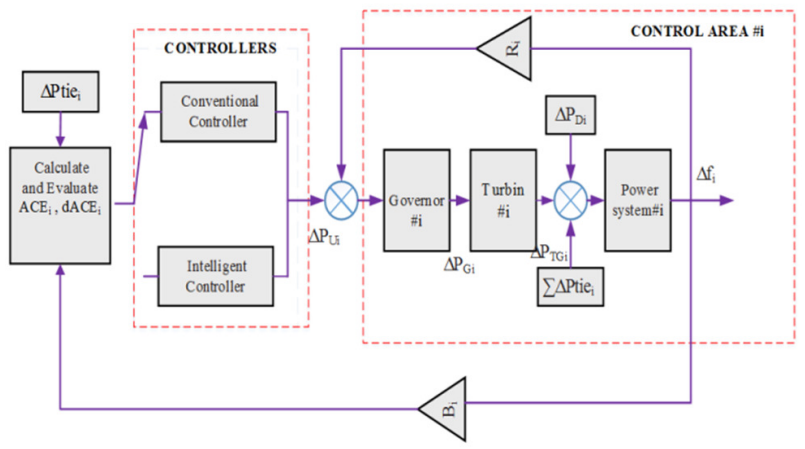

Fig. 6. The structure of the control area $\# i$ using different controllers.

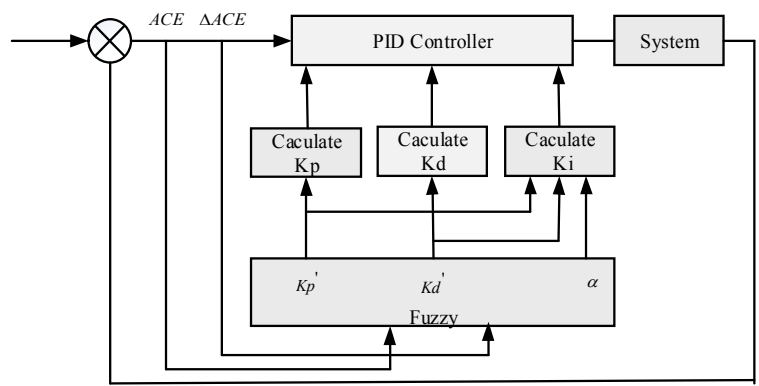

Fig. 7. The structure of the fuzzy - PID controller.

The fuzzy controller designed with ACE and $\triangle \mathrm{ACE}$ inputs has the membership functions presented in Figures 8-10 and Tables I-III. The outputs of the fuzzy set are $K_{p}{ }^{\prime}, K_{d}{ }^{\prime}$ and $\alpha$.

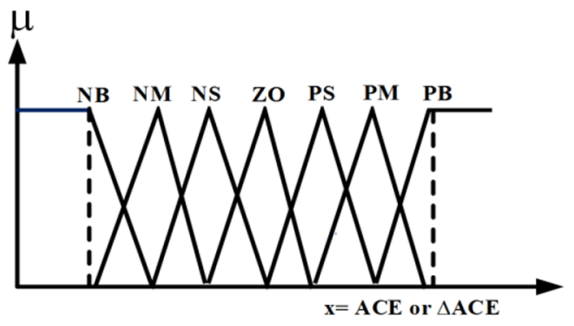

Fig. 8. Membership function of $\mathrm{ACE}$ and $\triangle \mathrm{ACE}$ 


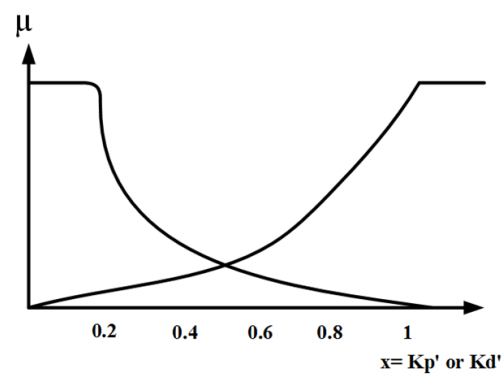

Fig. 9. Membership function of Kp', Kd'.

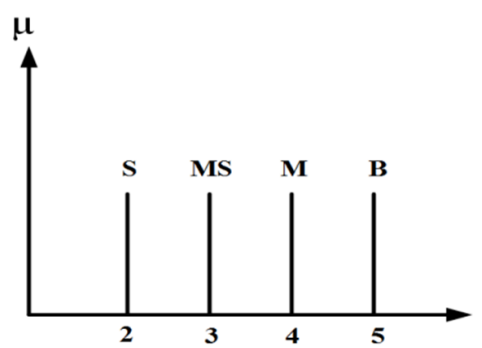

Fig. 10. Membership function of $\alpha$.

TABLE I. FUZZY RULE FOR $K_{p}{ }^{\prime}$

\begin{tabular}{|c|c|c|c|c|c|c|c|c|}
\hline \multicolumn{9}{|c|}{$\Delta$ ACE } \\
\hline \multicolumn{1}{|c|}{} & NB & NM & NS & ZO & PS & PM & PB \\
\hline \multirow{4}{*}{ ACE } & NB & S & S & S & S & S & S & S \\
\cline { 2 - 10 } & NM & B & B & S & S & S & B & B \\
\cline { 2 - 10 } & NS & B & B & B & S & B & B & B \\
\cline { 2 - 10 } & ZO & B & B & B & B & B & B & B \\
\cline { 2 - 9 } & PS & B & B & B & S & B & B & B \\
\cline { 2 - 9 } & PM & B & B & S & S & S & B & B \\
\cline { 2 - 9 } & PB & S & S & S & S & S & S & S \\
\hline
\end{tabular}

TABLE II. FUZZY RULE FOR $K_{d}^{\prime}$

\begin{tabular}{|c|c|c|c|c|c|c|c|c|}
\hline \multicolumn{9}{|c|}{$\triangle \mathbf{A C E}$} \\
\hline & & NB & NM & NS & $\mathrm{ZO}$ & PS & PM & $\mathrm{PB}$ \\
\hline \multirow{7}{*}{ ACE } & NB & B & B & B & B & B & B & B \\
\hline & $\mathrm{NM}$ & $\mathrm{S}$ & $\mathrm{B}$ & $\mathrm{B}$ & B & $\mathrm{B}$ & $\mathrm{B}$ & $S$ \\
\hline & NS & $\mathrm{S}$ & $\mathrm{S}$ & $\mathrm{B}$ & B & B & $\mathrm{S}$ & $\mathrm{S}$ \\
\hline & $\mathrm{ZO}$ & $\mathrm{S}$ & $S$ & $\mathrm{~S}$ & $\mathrm{~B}$ & $\mathrm{~S}$ & $\mathrm{~S}$ & $\mathrm{~S}$ \\
\hline & PS & $\mathrm{S}$ & $\mathrm{S}$ & B & B & B & $\mathrm{S}$ & $\mathrm{S}$ \\
\hline & PM & $\mathrm{S}$ & $B$ & B & B & B & $B$ & $\mathrm{~S}$ \\
\hline & PB & B & B & B & B & B & B & B \\
\hline
\end{tabular}

TABLE III. FUZZY RULE FOR $a$

\begin{tabular}{|c|c|c|c|c|c|c|c|c|}
\hline \multicolumn{9}{|c|}{$\triangle \mathbf{A C E}$} \\
\hline & & NB & NM & NS & $\mathrm{ZO}$ & PS & PM & PB \\
\hline \multirow{7}{*}{ ACE } & NB & 2 & 2 & 2 & 2 & 2 & 2 & 2 \\
\hline & NM & 3 & 3 & 2 & 2 & 2 & 3 & 3 \\
\hline & NS & 4 & 3 & 3 & 2 & 3 & 3 & 4 \\
\hline & $\mathrm{ZO}$ & 5 & 4 & 3 & 3 & 3 & 4 & 5 \\
\hline & PS & 4 & 3 & 3 & 2 & 3 & 3 & 4 \\
\hline & PM & 3 & 3 & 2 & 2 & 2 & 3 & 3 \\
\hline & PB & 2 & 2 & 2 & 2 & 2 & 2 & 2 \\
\hline
\end{tabular}

From (5), (6) and (8) the following equations can be deduced:

$$
K_{p}=\left(K_{p \max }-K_{p \min }\right) K_{p}^{\prime}+K_{p \min }
$$

$$
\begin{gathered}
K_{d}=\left(K_{\mathrm{d} \max }-K_{d \min }\right) K_{d}^{\prime}+K_{d \min } \\
K_{i}=K_{p}{ }^{2} /\left(\alpha T_{d}\right)
\end{gathered}
$$

The above factors will be applied when running the PID like fuzzy logic controller in dealing with the load frequency control of an interconnected power system.

\section{CASE STUdies}

This section presents numerical simulations implemented in MATLAB/Simulink considering numerous perspectives to demonstrate the proposed control strategy. The simulation scenarios describe a system encountered with nonlinearities, variation of different load types, uncertainties, and time delay. The system parameters used in the simulations are described in the Appendix (Table VI). The proposed controller is compared with GA PI [16], BFOA PI [16], BFOA-PSO optimized PI [17], fuzzy PI [18], and FPID [19] controllers to verify its control quality.

A. Performance Comparison under Step Load, Pulse Load, Random Load, and Sinusoidal Load Disturbances.

In a power system, the electrical energy at the power supply is taken from generators and imported energy sources. The electrical energy is supplied to consumers, production plants, energy for export, or is lost on the transmission line. When the supplied electrical energy is greater than the consumed energy, the system frequency will increase, otherwise, it will decrease. In fact, due to the large changes of the load, the frequency of the system changes continuously affecting the equipment in the system such as: AC motors, tranformers, steam turbines, etc. The types of load disturbance are shown in Figure 11.

- Step load disturbance : $\Delta P_{d 1}=\Delta P_{d 2}=0.03(\mathrm{pu})$.

- Pulse load disturbance: $\Delta P_{d 1}=\Delta P_{d 2}=0.03(\mathrm{pu})$, period: $40 \mathrm{~s}$, and pulse width: $10 \%$.

- Random load disturbance: $\Delta_{d 1}=\Delta P_{d 2}=0.03(\mathrm{pu})$, sample time: $40 \mathrm{~s}$.

- Sinusoidal load disturbance: $\Delta_{d 1}=\Delta P_{d 2}=0.03 \sin (0.0628 t)$

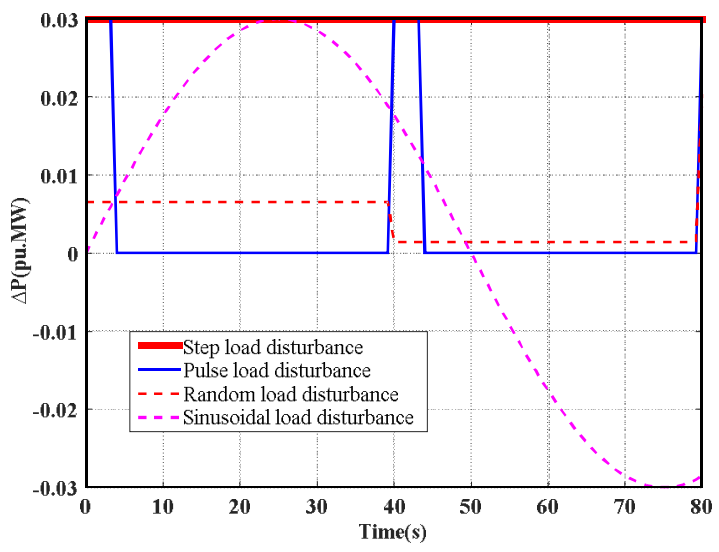

Fig. 11. Load disturbance types. 
The proposed fuzzy PID controller was compared with GA PI [16], BFOA PI [16], BFOA-PSO optimized PI controller [17], fuzzy PI [18], and FPID [19] controllers and the results are shown in Table IV. We see that minimum ITAE value and minimum settling time in frequency deviations are obtained with the fuzzy PID controller.

(a)

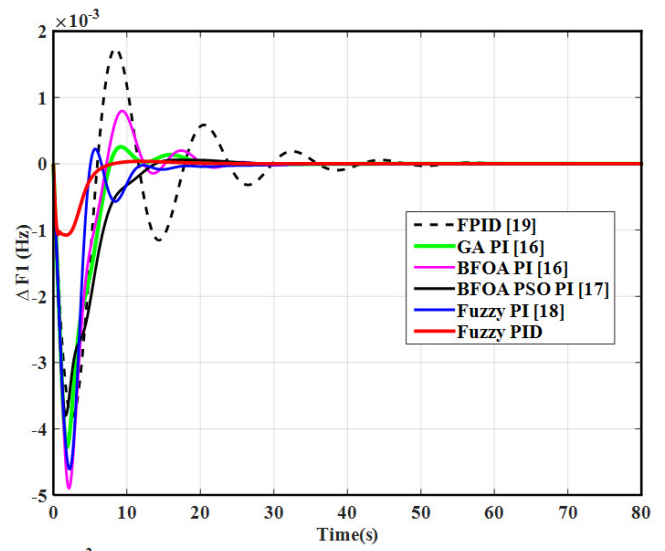

(b)

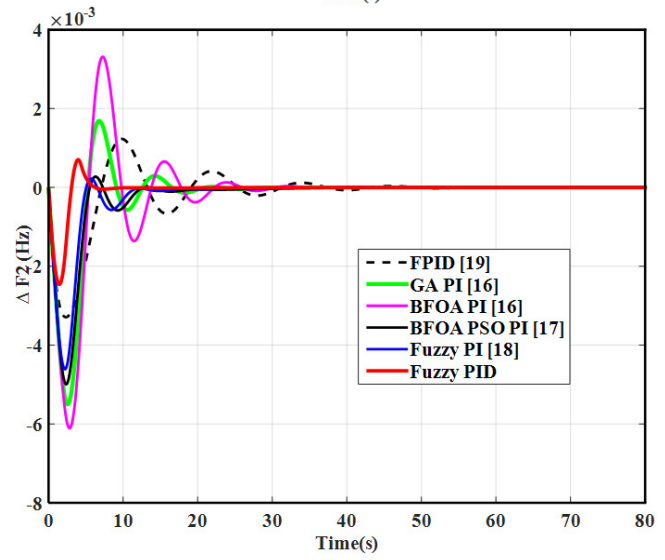

Fig. 12. Dynamic responses to the step load disturbance in two areas: (a) $\Delta F_{1}$, (b) $\Delta F_{2}$

The step load disturbance in two areas and the system dynamic response are shown in Figure 12 along with the simulation results of the tested controllers on the same power system. Critical analysis of the dynamic responses clearly reveals that significant improvement is observed with the proposed fuzzy PID controller.

TABLE IV. COMPARATIVE PERFORMANCE OF ERROR AND SETTLING TIME UNDER STEP LOAD DISTURBANCES

\begin{tabular}{|c|c|c|c|}
\hline \multirow{2}{*}{ Techniques/parameters } & \multirow{2}{*}{ ITAE } & \multicolumn{2}{|c|}{ Settling $\boldsymbol{T} \boldsymbol{s}$ (s) } \\
\cline { 3 - 4 } & & $\boldsymbol{\Delta}_{\boldsymbol{1}}$ & $\boldsymbol{\Delta} \boldsymbol{F}_{\mathbf{2}}$ \\
\hline FPID [19] & 12.07 & 40.01 & 40.67 \\
\hline GA PI [16] & 7.16 & 17.89 & 19.01 \\
\hline BFOA PI [16] & 7.01 & 19.14 & 24.26 \\
\hline BFOA PSO PI [17] & 5.08 & 12.80 & 16.98 \\
\hline Fuzzy PI [18] & 3.44 & 13.11 & 11.07 \\
\hline Fuzzy PID & 0.84 & 6.02 & 5.83 \\
\hline
\end{tabular}

The expression for the ITAE objective function is:

$$
\text { ITAE }=\int_{0}^{t_{\operatorname{sim}}}\left(\left|\Delta F_{1}\right|+\left|\Delta F_{2}\right|+\left|\Delta P_{\text {tie }}\right|\right) \cdot t \cdot d t
$$

(a)

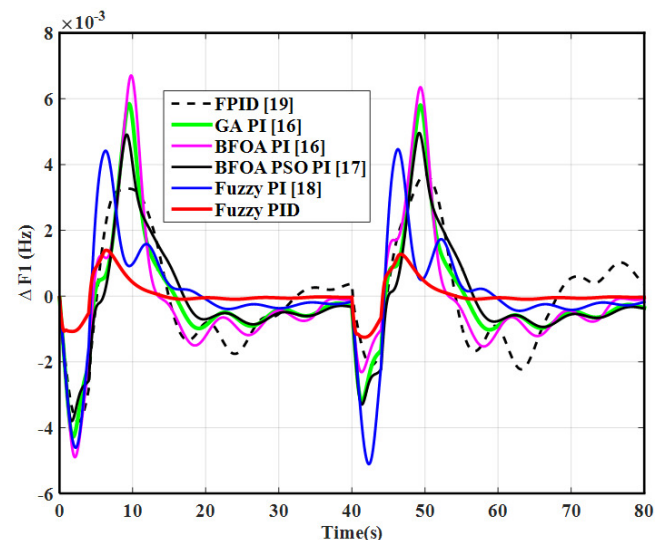

(b)

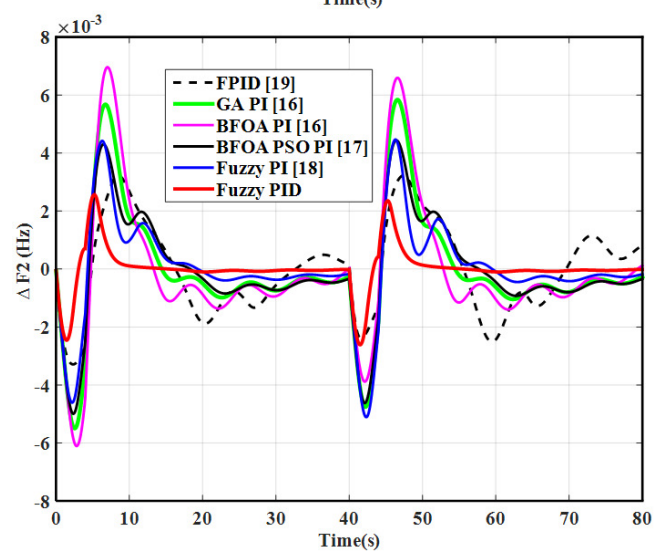

Fig. 13. Dynamic responses to the pulse load disturbance in two areas: (a) $\Delta F_{1}$, (b) $\Delta F_{2}$.

The simulation results shown in Figures 12-15 show that the output response of the frequency difference of the two areas has a settling time of about 7 to 10 s, the overshoot is very low and the frequency oscillation does not exist when using the proposed fuzzy - PID controller. These results prove the optimality of the proposed controller. In this section, when the system faces different types of load disturbances, the undesirable effects will be minimized under the active capability of the suggested controller.

\section{B. System Simulations Considering Nonlinear System Components and Uncertainty Parameters}

It is a fact that nonlinear components such as GDB and GRC along with the uncertainties of parameters are highly suitable for practical control systems. A real interconnected power system must naturally include such components. Nonlinearities, GDB and GRC, may concern directly the operation of the power system. In the meantime, the uncertainties regarding the variation of system parameters as illustrated in Table V obviously affect the stability of the power system. In this subsection, these undesired effects will be minimized under the positive influence of the proposed PIDlike fuzzy logic controller. 
(a)

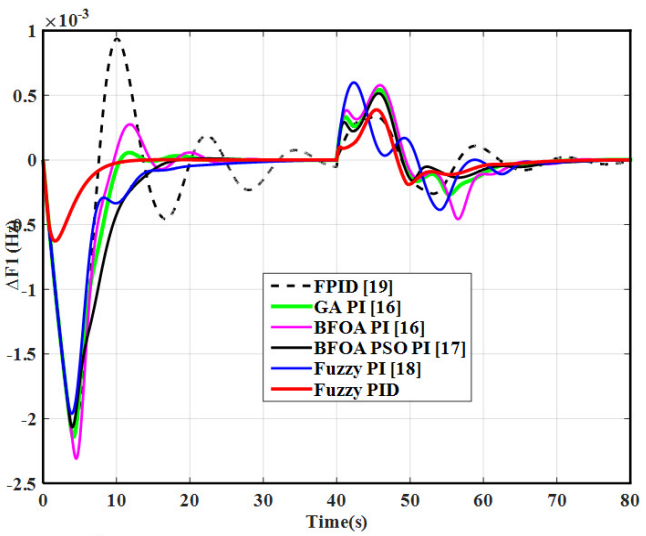

(b)

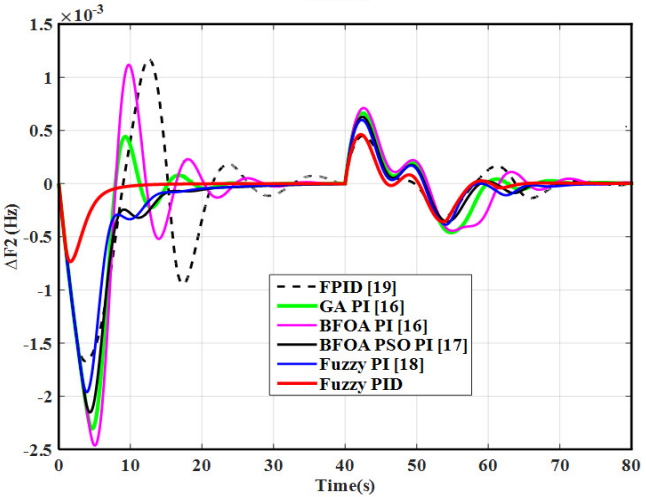

Fig. 14. Dynamic responses to the random load disturbance in two areas: (a) $\Delta F_{1}$, (b) $\Delta F_{2}$

(a)

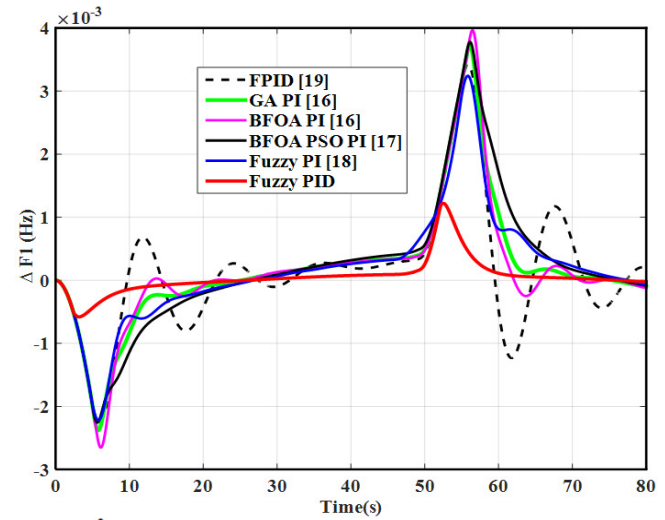

(b)

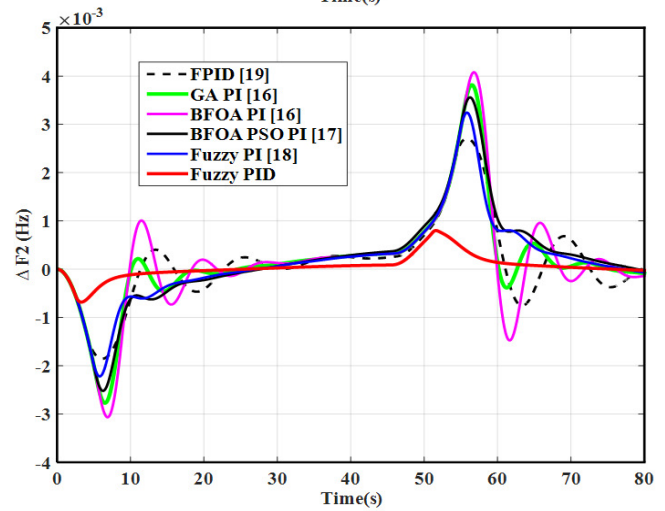

Fig. 15. Dynamic responses to the sinusoidal load disturbance in two areas: (a) $\Delta F_{1}$, (b) $\Delta F_{2}$
Simulation results when embedding nonlinearities and uncertainties are exhibited in Table V and Figure 16. As can be seen, the negative influences of these variations are successfully limited. Both the frequency and tie-line power deviations are still rejected with good control performance, i.e. low overshoots and short settling times. These results demonstrate the robustness of the proposed fuzzy logic-based load-frequency controller.

\section{TABLE V. PARAMETER VARIATIONS}

\begin{tabular}{|c|c|}
\hline Tg1 & $0.1 \pm 0.1 * 50 \%$ \\
\hline Tg2 & $0.2 \pm 0.1 * 50 \%$ \\
\hline M1 & $10 \pm 0.1 * 50 \%$ \\
\hline D1 & $1 \pm 1 * 50 \%$ \\
\hline M2 & $10 \pm 0.1 * 50 \%$ \\
\hline D2 & $1 \pm 1 * 50 \%$ \\
\hline GRC & $5 \%$ \\
\hline GDB & $5 \%$ \\
\hline
\end{tabular}

(a)

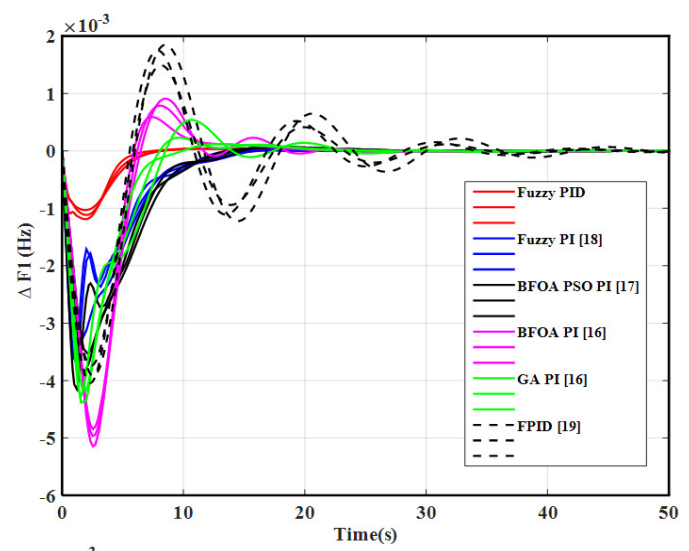

(b)

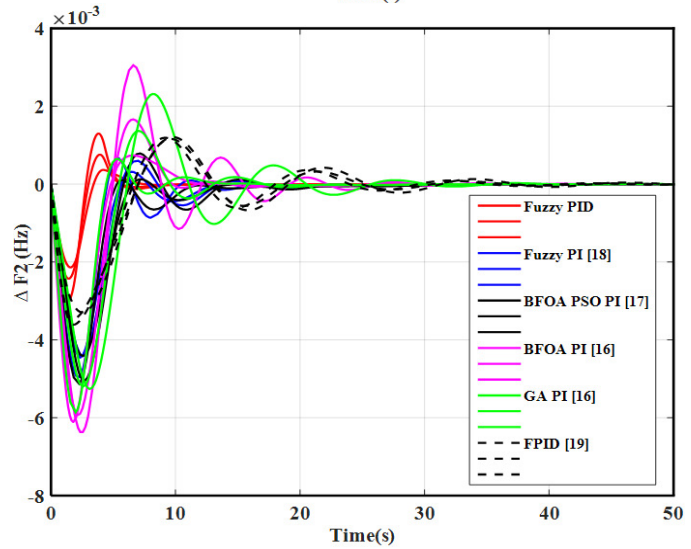

Fig. 16. Dynamic responses to the step load disturbance in two areas (with uncertainty parameters): (a) $\Delta F_{1}$, (b) $\Delta F_{2}$.

C. Performance Comparison with Time - Delay $=0.2 \mathrm{~s}$ and $\Delta P_{d 1}=\Delta P_{d 2}=0.03$ (Step Load)

Time delay is another crucial parameter affecting the operation of a power system. Long time delay may be detrimental to system stability and may degrade system performance. From Figure 17, it is obvious that the damping characteristics obtained by the proposed fuzzy - PID controller are the best among the results. 
(a)

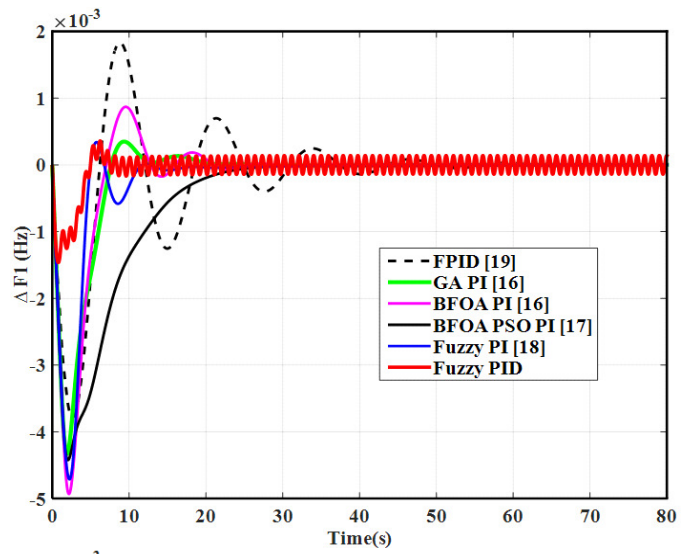

(b)

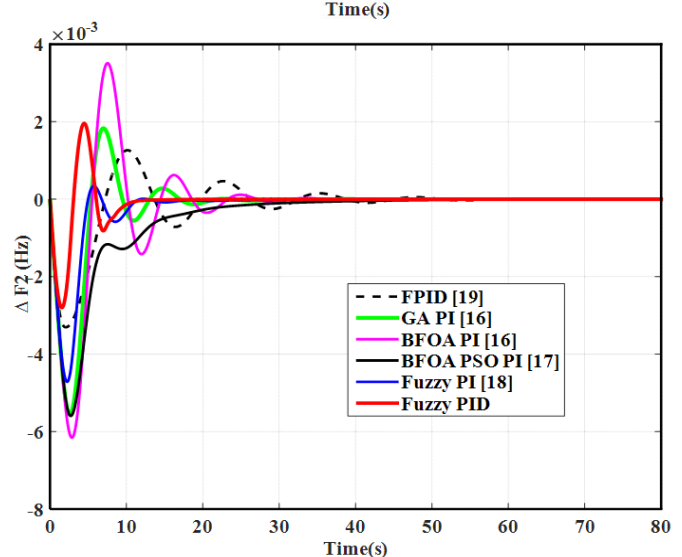

Fig. 17. Dynamic responses to the step load disturbance in two areas (with time delay): (a) $\Delta F_{1}$, (b) $\Delta F_{2}$.

\section{CONCLUSION AND FURTHER WORK}

In this paper, a comparative evaluation has been performed to examine the effectiveness of the proposed fuzzy -PID controller. In order to provide realistic results, the proposed and five known controllers, namely the FPID, GA PI, BFOA PI, and the fuzzy PI controllers were validated on a two-area thermal unit power system in which the physical constraints of the GRC, GDB, and uncertainty have been taken into consideration. A rule-based scheme for gain scheduling of the PID controller is proposed for process control. The new scheme utilizes fuzzy rules and reasoning to determine the controller parameters and the PID controller generates the control signal. Comparative dynamic performance evaluations have been carried out under step, pulse, sinusoidal, and random load perturbation patterns. The results demonstrate that the fuzzy - PID controller achieves much better dynamic performance (largest minimum damping ratio, smallest IATE value, smallest overshoots, and smallest settling times of the area frequency oscillations). It is confirmed that the proposed fuzzy - PID controller outperforms many existing counterparts such as the FPID, GA PI, BFOA PI, BFOA PSO PI, and fuzzyPI controller in stabilizing the system. Future work will focus on finding a new method to determine significant factors, namely $K_{\text {pmin }}, K_{\text {pmax }}, K_{d \min }$ and $K_{d \max }$. In this context, an effective optimization method should be taken into account.

\section{APPENDIX}

Description of a Two-Area Interconnected Power System in a State-Space Form

State Variables:

$$
\begin{array}{lll}
x_{1}=\Delta f_{1} & x_{2}=\Delta P_{t 1} & x_{3}=\Delta P_{g 1} \\
x_{4}=\Delta f_{2} & x_{5}=\Delta P_{t 2} & x_{6}=\Delta P_{r 2} \\
x_{7}=\Delta P_{g 2} & x_{8}=\Delta P_{t i e}(1,2) & x_{9}=\int A C E_{1} d t \\
x_{10}=\int A C E_{2} d t &
\end{array}
$$

Control inputs: $u_{1}, u_{2}$

Disturbance inputs: $\quad d_{1}=\Delta P_{L 1}, \quad d_{2}=\Delta P_{L 2}$

The state vector ' $x$ ' $(10 \times 1)$, control vector ' $u$ ' $(2 \times 1)$, and the disturbance vector ' $d$ ' $(2 \times 1)$ are:

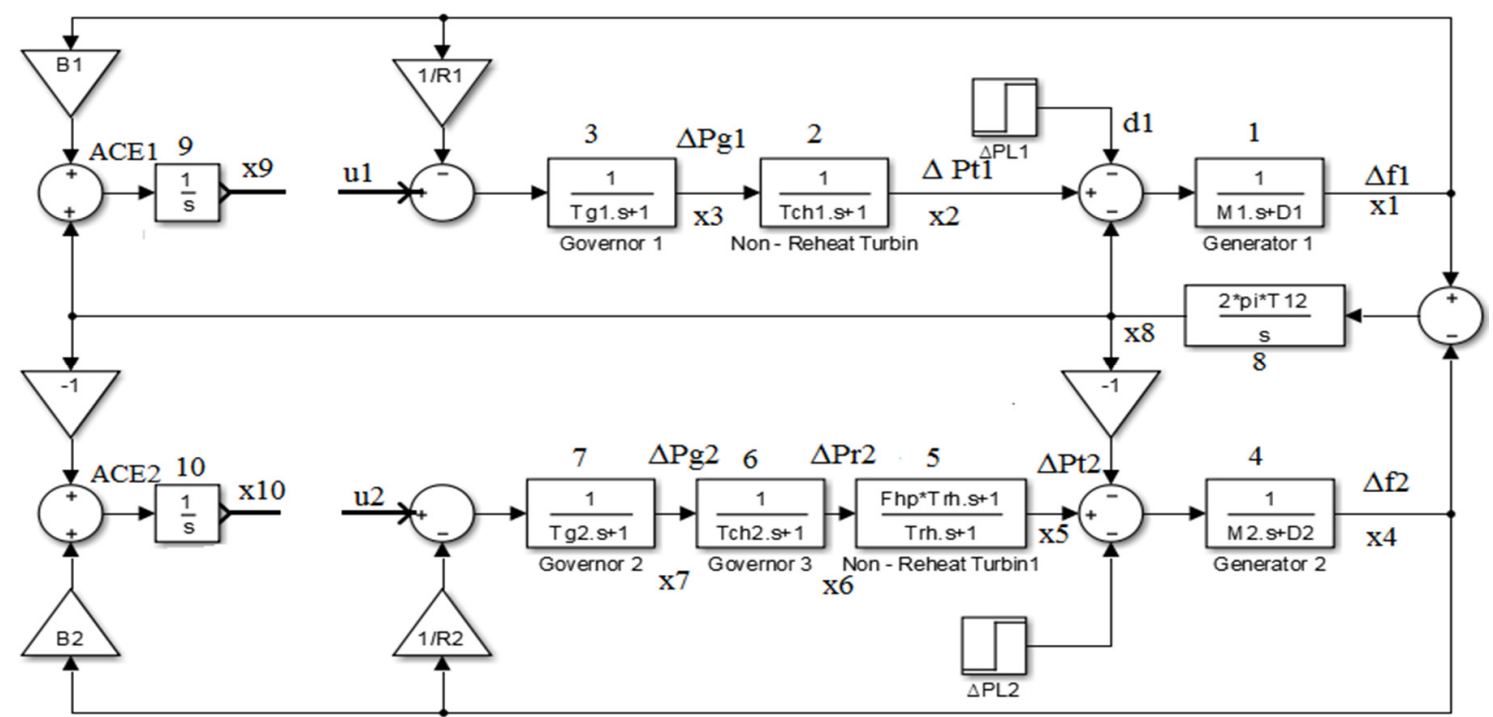

Fig. 18. Block diagram of a two-area interconnected non-reheat thermal- reheat thermal power system used to find the state-space of the system. 


$$
\begin{aligned}
& x=\left[\begin{array}{llllllllll}
x_{1} & x_{2} & x_{3} & x_{4} & x_{5} & x_{6} & x_{7} & x_{8} & x_{9} & x_{10}
\end{array}\right] \\
& u=\left[\begin{array}{l}
u_{1} \\
u_{2}
\end{array}\right] \quad d=\left[\begin{array}{l}
d_{1} \\
d_{2}
\end{array}\right]
\end{aligned}
$$

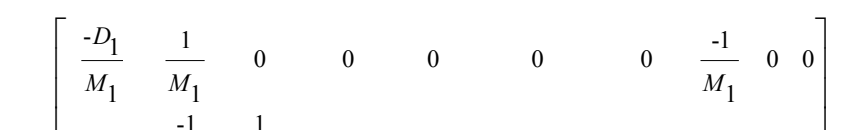

$$
\begin{aligned}
& 0 \quad \frac{-1}{T c h_{1}} \frac{1}{T c h_{1}} \quad 0 \quad 0 \quad 0 \quad 00000
\end{aligned}
$$

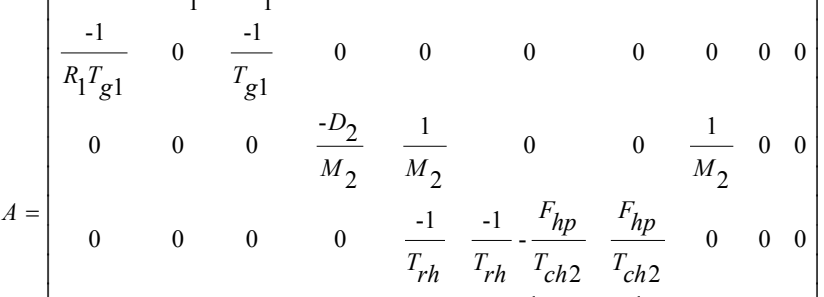

$$
\begin{aligned}
& {\left[\begin{array}{cccccccccc}
0 & 0 & 0 & 0 & 0 & \frac{-1}{T_{c h 2}} & \frac{1}{T_{c h 2}} & 0 & 0 & 0 \\
0 & 0 & 0 & \frac{-1}{R_{2} T_{g 2}} & 0 & 0 & \frac{-1}{T_{g 2}} & 0 & 0 & 0 \\
2 \pi T_{12} & 0 & 0 & -2 \pi T_{12} & 0 & 0 & 0 & 0 & 0 & 0 \\
B_{1} & 0 & 0 & 0 & 0 & 0 & 0 & 1 & 0 & 0 \\
0 & 0 & 0 & B_{2} & 0 & 0 & 0 & 1 & 0 & 0
\end{array}\right]} \\
& B=\left[\begin{array}{cc}
0 & 0 \\
0 & 0 \\
\frac{1}{T_{g 1}} & 0 \\
0 & 0 \\
0 & 0 \\
0 & 0 \\
0 & \frac{1}{T_{g}} \\
0 & 0 \\
0 & 0 \\
0 & 0
\end{array}\right] \quad \Gamma=\left[\begin{array}{cc}
\frac{-1}{M_{1}} & 0 \\
0 & 0 \\
0 & 0 \\
0 & \frac{-1}{M_{2}} \\
0 & 0 \\
0 & 0 \\
0 & 0 \\
0 & 0 \\
0 & 0 \\
0 & 0
\end{array}\right]
\end{aligned}
$$

Parameters of a Two-Area Interconnected Power System

TABLE VI. THE PARAMETERS OF THE TWO AREAS [19]

\begin{tabular}{|c|c|c|c|}
\hline $\begin{array}{c}\text { Area with non- } \\
\text { reheat turbine }\end{array}$ & Value & $\begin{array}{c}\text { Area with } \\
\text { reheat turbine }\end{array}$ & Value \\
\hline$M_{l}$ (p.u.s) & 10 & $M_{2}$ (p.u.s) & 10 \\
\hline$D_{l}$ (p.u./Hz) & 1 & $D_{2}$ (p.u./Hz) & 1 \\
\hline$T_{c h 1}$ (s) & 0.3 & $T_{c h 2}(\mathrm{~s})$ & 0.3 \\
\hline$T_{g l}$ (s) & 0.1 & $T_{g 2}$ (s) & 0.2 \\
\hline$R_{l}$ (Hz/p.u.) & 0.05 & $R_{2}$ (Hz/p.u.) & 0.05 \\
\hline$B_{l}$ (p.u./Hz) & 21 & $B_{2}$ (p.u./Hz) & 21 \\
\hline$T_{l}$ (p.u./rad.) & 22.6 & $T_{2}$ (p.u./rad.) & 22.6 \\
\hline & & $F_{h p}$ & 0.3 \\
\hline & & $T_{r h}(\mathrm{~s})$ & 7 \\
\hline
\end{tabular}

\section{REFERENCES}

[1] N. Nguyen, Q. Huang, and T.-M.-P. Dao, "Modeling and control of a 6control-area interconnected power system to protect the network frequency applying different controllers," Turkish Joural Of Electrical Engineering And Computer Sciences, vol. 24, pp. 2205-2219, 2016, https://doi.org/10.3906/elk-1403-78.

[2] W. Tan, H. Zhang, and M. Yu, "Decentralized load frequency control in deregulated environments," International Journal of Electrical Power \& Energy Systems, vol. 41, no. 1, pp. 16-26, Oct. 2012, https://doi.org/ 10.1016/j.ijepes.2012.02.013.

[3] Y. Sun, Y. Wang, Z. Wei, G. Sun, and X. Wu, "Robust Ho load frequency control of multi-area power system with time delay: a sliding mode control approach," IEEE/CAA Journal of Automatica Sinica, vol. 5, no. 2, pp. 610-617, Mar. 2018, https://doi.org/10.1109/ JAS.2017.7510649.

[4] N. E. L. Yakine Kouba, M. Menaa, M. Hasni, and M. Boudour, "Load Frequency Control in multi-area power system based on Fuzzy LogicPID Controller," in 2015 IEEE International Conference on Smart Energy Grid Engineering (SEGE), Oshawa, Canada, Aug. 2015, pp. 1-6, https://doi.org/10.1109/SEGE.2015.7324614.

[5] V. S. Sundaram and T. Jayabarathi, "An artificial neural network approach of load frequency control in a multi area interconnected power system," Elixir Electrical Engineering, vol. 38, pp. 4394-4397, 2011.

[6] H. K. Shaker, H. E. Zoghby, M. E. Bahgat, and A. M. Abdel-Ghany, "Advanced Control Techniques for an Interconnected Multi Area Power System for Load Frequency Control," in 2019 21st International Middle East Power Systems Conference (MEPCON), Cairo, Egypt, Dec. 2019, pp. 710-715, https://doi.org/10.1109/MEPCON47431.2019.9008158.

[7] R. K. Sahu, S. Panda, and G. T. Chandra Sekhar, "A novel hybrid PSOPS optimized fuzzy PI controller for AGC in multi area interconnected power systems," International Journal of Electrical Power \& Energy Systems, vol. 64, pp. 880-893, Jan. 2015, https://doi.org/10.1016/ j.ijepes.2014.08.021.

[8] T. Kerdphol, F. S. Rahman, and Y. Mitani, "Virtual Inertia Control Application to Enhance Frequency Stability of Interconnected Power Systems with High Renewable Energy Penetration," Energies, vol. 11, no. 4, Apr. 2018, Art. no. 981, https://doi.org/10.3390/en11040981.

[9] D. Guha, P. K. Roy, and S. Banerjee, "Load frequency control of large scale power system using quasi-oppositional grey wolf optimization algorithm," Engineering Science and Technology, an International Journal, vol. 19, no. 4, pp. 1693-1713, Dec. 2016, https://doi.org/ 10.1016/j.jestch.2016.07.004.

[10] M. Gheisarnejad and M. H. Khooban, "Design an optimal fuzzy fractional proportional integral derivative controller with derivative filter for load frequency control in power systems," Transactions of the Institute of Measurement and Control, vol. 41, no. 9, pp. 2563-2581, Jun. 2019, https://doi.org/10.1177/0142331218804309.

[11] D. Qian and G. Fan, "Neural-Network-Based Terminal Sliding Mode Control for Frequency Stabilization of Renewable Power Systems," IEEE/CAA Journal of Automatica Sinica, vol. 5, no. 3, pp. 706-717, May 2018, https://doi.org/10.1109/JAS.2018.7511078.

[12] A. B. Kunya, M. Argin, and S. Kucuksari, "Optimal Load Frequency Control of Multi-Area Power System Considering Incremental Control Action," in 2019 IEEE Texas Power and Energy Conference (TPEC), College Station, TX, USA, Feb. 2019, pp. 1-6, https://doi.org/ 10.1109/TPEC.2019.8662140.

[13] J. Morsali, K. Zare, and M. Tarafdar Hagh, "Comparative performance evaluation of fractional order controllers in LFC of two-area diverse-unit power system with considering GDB and GRC effects," Journal of Electrical Systems and Information Technology, vol. 5, no. 3, pp. 708722, Dec. 2018, https://doi.org/10.1016/j.jesit.2017.05.002.

[14] D. K. Sahoo, R. K. Sahu, G. T. C. Sekhar, and S. Panda, "A novel modified differential evolution algorithm optimized fuzzy proportional integral derivative controller for load frequency control with thyristor controlled series compensator," Journal of Electrical Systems and Information Technology, vol. 5, no. 3, pp. 944-963, Dec. 2018, https://doi.org/10.1016/j.jesit.2016.12.003. 
[15] Z.-Y. Zhao, M. Tomizuka, and S. Isaka, "Fuzzy gain scheduling of PID controllers," IEEE Transactions on Systems, Man, and Cybernetics, vol. 23, no. 5, pp. 1392-1398, Sep. 1993, https://doi.org/10.1109/21.260670.

[16] E. S. Ali and S. M. Abd-Elazim, "Bacteria foraging optimization algorithm based load frequency controller for interconnected power system," International Journal of Electrical Power \& Energy Systems, vol. 33, no. 3, pp. 633-638, Mar. 2011, https://doi.org/10.1016/j.ijepes. 2010.12.022.

[17] S. Panda, B. Mohanty, and P. K. Hota, "Hybrid BFOA-PSO algorithm for automatic generation control of linear and nonlinear interconnected power systems," Applied Soft Computing, vol. 13, no. 12, pp. 47184730, Dec. 2013, https://doi.org/10.1016/j.asoc.2013.07.021.

[18] A. Kandhavel, "Load frequency control," Mathworks, 2011. https://www.mathworks.com/matlabcentral/fileexchange/31514-loadfrequency-control (accessed Aug. 12, 2021).

[19] S. A. Taher, M. Hajiakbari Fini, and S. Falahati Aliabadi, "Fractional order PID controller design for LFC in electric power systems using imperialist competitive algorithm," Ain Shams Engineering Journal, vol. 5, no. 1, pp. 121-135, Mar. 2014, https://doi.org/10.1016/j.asej.2013. 07.006 . 